Enxoto de imagens luxuriantes: o processo de escrita em Angústia, de

\title{
Graciliano Ramos
}

Fabiano Vale ${ }^{1}$

RESUMO: O presente artigo trata do processo de escrita em Angústia, de Graciliano Ramos, publicado em 1936, no plano da enunciação, mo rfoló gico, sintático e co mposicional-narrativo. Entendê-los significa apreender a dinâmica literária no plano do conteúdo e da forma. Essa dinâmica pode apontar para uma outra dinâmica externa, tendo como mediação a literatura, materializada no trabalho do escritor, que é a obra em si.

ABSTRACT: This article discusses the writing process in Angústia, Graciliano Ramos, published in 1936, in terms of enunciation, morphological, syntactic and compositional-narrative. Understand them means to grasp the dynamics in terms of literary content and form. This dynamic can point to another external dyna mics, with the mediation literature, embodied in the writer's work, which is the work itself.

PALAVRAS-CHAVE: Processo; Escrita; Imobilidade; Angústia; Graciliano Ramos KEYW ORDS: Process, Writing, immobility; Angústia; Graciliano Ramos

Em duas horas escrevo uma palavra: Marina. Depois, aproveitando letras deste nome, arranjo coisa, absurdas: ar, mar, rima, arma, ira, amar. Uns vinte nomes. Quando não consigo formar combinações novas traço rabiscos que representam uma espada, uma lira uma cabeça de mulher e outros disparates. Penso em indivíduos e em objetos que não têm relação com os desenhos: processos, orçamentos, o diretor, o secretário, políticos, suje itos remediados que me desprezam porque sou um pobre-diabo. (RAMOS, 2003, p. 6).

O processo de escrita é mostrado como angustiante a todo momento nesta obra. De igual modo que tal mecanismo é evidenciado no plano do conteúdo o é, também, no plano da forma. A princípio, se mostra delirante, caótico, condensado, mas que, com o desenvolver da narrativa, "sombras" informes ganham contornos: "Das visões que me

\footnotetext{
1 Mestrando em Teoria Literária e Literatura Brasileira pelo Departamento de Teoria Literária e Literaturas da Universidade de Brasília (TEL/UnB). E-mail: fabianocostavale@gmail.com
} 
perseguiam naquelas noites compridas umas sombras permanecem, sombras que se misturam à realidade e me produzem calafrios" (RAMOS, 2003, p. 5).

Essas sombras são as "criaturas" que Luís da Silva não suporta e os "lugares" que se lhe tornam odiosos. Percebe-se, portanto, o quanto a escrita, desde já, é um processo que lhe custa caro, e deixa marcas, tanto no ato da escrita como no tema da matéria narrada: “As mãos já não são minhas: são mãos de velho, fracas e inúteis. As escoriações das palmas cicatrizaram. Impossível trabalhar" (RAMOS, 2003, p. 5).

As escoriações cicatrizaram, mas deixaram marcas. Essas cicatrizes, da mesma forma que marcaram Ulisses e permitiram a sua identificação, aqui elas também sinalizam e identificam os atos cometidos pelo personagem-autor, constituindo marcas tipográficas à personagem, à enunciação e ao enunciado.

Evidente no plano do conteúdo, o processo se descortina também no da forma. Inclusive, é no nível mórfico que o vemos com maior força. O nome de Marina, por exemplo, é decomposto, tendo suas letras combinadas para constituírem outras palavras: '[...] Marina. Depois, aproveitando letras deste nome, arranjo coisa, absurdas: ar, mar, rima, arma, ira, amar" (RAMOS, 2003, p. 6). Cessadas as combinações, como mesmo afirma o narrador-protagonista, passa-se para os desenhos, dos rabiscos a outras palavras, imagens e assuntos que estarão presentes ou serão retomados ao longo do romance.

Esta ação, em princípio, pode parecer somente um sintoma do estado mental do personagem, sem motivo aparente ou com razões estritamente psicológicas. No entanto, ela demonstra, mimeticamente, o que será feito em toda narrativa, seja em seu nível mais elementar, a palavra, ou no mais complexo, a própria estrutura composicional do romance.

Portanto, o processo de escrita se evidencia em todos os elementos da enunciação, seja do mais particular ao mais geral, partindo do mórfico, passando pelo sintático e chegando ao composicional narrativo. Entendê-los significa apreender a dinâmica mesma da obra, tanto no plano dos seus conteúdos quanto no da forma. Uma vez descrita, essa dinâmica pode apontar para uma outra dinâmica externa, tendo como mediação a literatura, materializada no trabalho do escritor, que é a obra em si.

Nesse sentido, o presente artigo tem como meta analisar a fatura da obra, em sua relação íntima com a realidade, em especial, a realidade brasileira de 1930.

Para tanto, o texto será subdividido em tópicos, nos quais se buscará tratar dos movimentos próprios da narrativa em sua relação com a História. 


\section{Jogo de sombras: o movimento das metáforas}

A brincadeira com o nome de Marina feita por Luís da Silva, processo no qual resulta outras palavras "ar, mar, rima, arma, ira, amar", sugere-nos além do estado mental do protagonista, ora mencionado neste artigo, uma possível divisão temática da obra. Algo que se poderia denominar de "fases", tanto do romance em si quanto do personagem. O que marca essas mudanças é a metáfora, simbolizando cada momento pelo qual o livro e o personagem passam.

Sendo assim, "ar" significaria a etapa inicial, em que o leitor é posto a par do que ocorrera: “[...] julgo que ainda não me restabeleci completamente. Das visões que me perseguiam naquelas noites compridas umas sombras permanecem, sombras que se misturam à realidade e me produzem calafrios" (RAMOS, 2003, p. 5).

"Visões", "sombras" e "calafrios" dão o tom, pintam o quadro fantasmagórico que se seguirá. Logo, o que era informe ganha contorno, desanuvia-se aos poucos, forma "criaturas", coisas e "lugares": "Dinheiro e propriedades, as duas colunas mal impressas, caixilho, dr. Gouveia, Moisés, homem da luz, negociantes, políticos, diretor e secretário, Julião Tavares” (RAMOS, 2003, p. 7), brotam das sombras. Desenvolvidas, agora "essas sombras se arrastam com lentidão viscosa, misturando-se, formando um novelo confuso" (RAMOS, 2003, p. 7), tanto para quem acompanha a história quanto para o narrador.

"Mar" vai simbolizar o fluxo de idas e vindas na narrativa. Luís da Silva, por meio da enunciação, mergulhará em seu passado, buscando acontecimentos que justifiquem o presente ou suas ações futuras. Passado e presente, ou mesmo futuro, são duas ordens com as quais ele não pode conviver de um modo harmonioso. O trânsito entre es sas duas ordens tem como mediação metáforas de movimento. Daí a presença de palavras como "chuva", "bonde", "carro", "navio", relacionadas com o mesmo campo semântico de água e movimento. "O bonde roda para oeste, dirige-se ao interior. Tenho a impressão de que ele me vai levar ao meu município sertanejo" (RAMOS, 2003, p. 9).

"Rimas" têm a ver com o espelhamento que se encenará entre Luís da Silva e Julião Tavares. Esta relação mostrar-se-á bastante tensa, culminando, inclusive, no assassinato deste último por seu antagonista. O aparecimento do seu rival faz com que Luís perca sua paz, alterando o seu comportamento, e o romance entre numa outra fase.

Uma dinâmica diferente, portanto, crescerá até atingir proporções trágicas: "Atravancou-me o caminho, obrigou-me a paradas constantes, buliu-me com os nervos" (RAMOS, 2003, p. 42). Ao mesmo tempo em que tal tensão conduz a uma rivalidade 
entre eles, distanciando-os, também os aproxima, pois o que Luís da Silva odeia em Julião é o reflexo de seu desejo, uma vez que ele não pode ser um Julião Tavares e quer sê-lo.

O ódio, dessa forma, será o motor para as ações de Luís. A partir desse momento, uma série de objetos aparecerá na narrativa, anunciando o crime: "Vejo a figura sinistra de seu Evaristo enforcado e os homens que iam para a cadeia amarrados de cordas" (RAMOS, 2003, p. 14). Aqui, logo no início do romance, surge uma cena que é do final da obra: o enforcamento de Julião Tavares. Por isso, a "corda" insinua-se como "arma", o que equivale à fase de preparação e planejamento do assassinato: "E não tirava os olhos da parede manchada, do rodapé vermelho, do cano. - Um pedaço daquilo é arma terrível. Arma terrível, sim senhor, rebenta a cabeça de um homem" (RAMOS, 2003, p. 89).

Sendo assim, "enforcamentos", "canos" e "imagens de pessoas mortas" têm forte ligação com o termo "corda", arma que consumará o homicídio futuro.

Para se executar um ato, principalmente se este for um crime, faz-se necessário uma força psíquica para a sua concussão. Munido dessa força, o actante poderá, então, por cabo aos seus planos ilícitos. No caso do protagonista ora em análise, a "ira" é a força psíquica e moral urgente para a realização do crime, e esta ganha vigor a partir do momento em que Luís da Silva descobre que Marina está grávida de Julião Tavares:

Queria que ela me iludisse, jurasse que não havia acontecido nada. Mordi as mãos para não gritar. Afastei-me, como um bêbado. Mas o ventre disforme continuava a perseguir-me. Era-me necessário falar, ir ao café, libertar-me da obsessão, do ódio que me enchia (RAMOS, 2003, p. 130).

A afronta atinge um ponto insuportável. Agora, mais do que nunca, uma atitude deveria ser tomada. Era imperativo contornar tamanho disparate, humilhação, com uma ação que lhe devolva a honra subtraída: "Isto me cortava o coração e aumentava o meu ódio a Julião Tavares" (RAMOS, 2003, p. 131). A narrativa avança, e o ódio passa a ser a medida para todas as coisas e, principalmente, os outros. A ira é uma régua com a qual os demais personagens são mensurados: "Marina era instrumento e merecia compaixão. D. Adélia era instrumento e merecia compaixão. Julião Tavares era também instrumento, mas não tive pena dele. Senti foi o ódio que sempre me inspirou agora aumentado" (RAMOS, 2003, p. 136).

As fases pelas quais a obra passa, a atmosfera, os movimentos numa história imóvel, o espelhamento invejoso, as insinuações do crime, o ódio motivador são 
resultados da impossibilidade de Luís da Silva "amar", relacionar-se de uma forma harmoniosa e equilibrada com o seu semelhante diferente: "O amor para mim sempre fora uma coisa dolorosa, complicada e incompleta” (RAMOS, 2003, p. 97-98).

Se o amor era algo complicado para si, enxergá- lo no outro era motivo de inveja, ódio: "Não sei como aquelas criaturas se podiam amar assim em voz alta, sem ligar importância à curiosidade dos vizinhos" (RAMOS, 2003, p. 98). Estas criaturas, figuras que se movimentam num ambiente delirante, são imagens deformadas do outro, resultados de um olhar que não consegue apreender o semelhante em sua plenitude e igualdade, situação esta possível somente àqueles capazes de amar.

\section{O papel da descrição}

Penso em coisas percebidas vagamente: o gado, escuro de carrapatos, roendo a madeira do curral; o cavalo de fábrica, lazarento e com esparavões; bodes definhando na morrinha; o carro de bois apodrecendo; na catinga parda, manchas brancas de ossadas e vôo negro dos urubus (RAMOS, 2003, p. 26).

O cenário descrito é digno de Portinari: decadência e miséria. As imagens apresentadas resumem no que a fazenda da infância de Luís da Silva se transformou, assim como o seu passado, num grande cemitério, no qual tudo definha, apodrece, seca e morre.

Para chamar a atenção para o horror de tal situação, a narrativa é suspensa para que a descrição exerça o seu papel. Portanto, ela tem uma função clara em Angústia, que é a de chamar-nos a atenção para um processo desagregador, destrutivo, no qual a vida das pessoas é sugada para reaparecer de uma forma fantasmagórica nas coisas.

Já que se falou em pintura, cabe mostrar a técnica utilizada. Para isso, dois recursos foram imprescindíveis. O primeiro, de ordem estilística, é a metonímia: “o gado, escuro de carrapatos", "bodes definham na morrinha", "catinga parda", "manchas brancas de ossadas", "vôos negros dos urubus". As cores sobressaídas são a preta, branca e cinza. $\mathrm{O}$ negro simboliza a ruína que carcome a vida dos animais e a utilidade dos objetos, conduzindo-os à brancura da morte. Tudo isso compondo a cena cinza (mistura do branco e do preto) da caatinga, onde os seres apodrecem, definham, secame morrem.

Para marcar o movimento da descrição e a imobilidade da situação, percebe-se a mudança das formas nominais dos verbos, que sai do particípio "percebidas" para o gerúnd io "roendo", "definhando", "apodrecendo". Além dessas formas verbais estarem 
relacionadas com o passado, também denotam circunstâncias de ações que perduram no tempo.

Portanto, o gerúndio é a melhor forma que as expressa, congelando a cena e dando-lhe um aspecto imóvel e decadente à situação descrita ou ao que se quer chamar a atenção nela. Esta situação é de completa imobilidade, cujo único movimento possível que se encena é o próprio da narrativa, com as metonímias e formas nominais dos verbos, para caracterizar, contraditoriamente, uma realidade decadente, imóvel que caminha a passos largos para a morte.

David Lodge, em seu livro A arte da ficção, especificamente no capítulo "Ambientação", comenta que "as descrições de um bom romance nunca são apenas descrições" (LODGE, 2010, p. 66). Elas servem tanto para evidenciar as características do ambiente quanto das personagens, em que um esteja em função do outro. Parece evidente que o papel das descrições as sim se constitui em Angústia.

\section{A re presentação do outro em Angústia}

O outro de classe é um problema em Angústia, manifesto no modo como o personagem-autor o narra. Esta narrativa é conduzida pelo olhar de Luís da Silva, que tudo invade e modifica, como observa Antonio Candido. Dessa visão emerge uma situação conflituosa. Distante, a representação do outro torna-se um estorvo, um fim a que tem de se chegar.

No entanto, mesmo distante, este outro faz-se próximo, posto que sua existência não pode ser negada. Imperativo, até. "Os vagabundos, por exemplo. Parece-me que eles cresceram muito, e, aproximando-se de mim, não vão gemer peditórios: vão gritar, exigir, tomar-me qualquer co is a" (RAMOS, 2003, p. 5).

Já que sua existência é imprescindível, cabe agora tratá-lo, aproximá-lo em suma. E isso é feito por meio do processo de escrita, que tenta captar este outro em movimento, em suas características, particularidades, mesmo que contaminadas pela visão do protagonista: "Naturalmente gastei meses construindo esta Marina que vive dentro de mim, que é diferente da outra, mas se confunde com ela" (RAMOS, 2003, p. 64).

Portanto, para ser narrado, descrito, o outro tem de ser tornado coisa, matéria do ato da escrita, objeto a ser dominado e manipulado: "Em duas horas escrevo uma palavra: Marina. Depois, aproveitando letras deste nome, arranjo coisa, absurdas: ar, 
mar, rima, arma, ira, amar" (RAMOS, 2003, p. 6).

Distanciado e aproximado pelo mesmo processo de escrita, o outro só lhe tem serventia desde que seja propriedade: 'Parece-me que até certo ponto Moisés é propriedade minha" (RAMOS, 2003, p. 23). Na condição de propriedade, este outro pode ser formado e deformado. Informe, qualquer molde lhe cabe.

Sendo assim, o outro de classe, para Luís da Silva, é um problema no sentido em que seja algo a ser dominado, reduzido a coisa, para ter algum valor ou destituído dele.

\section{Imobilidade}

Quando vinha uma ideia, afastava-a, agarrava-me a outra, que saía logo. Algumas voltavam com insistência. As botinas de Lobisomem estavam cambadas. O espírito de Deus boiava sobre as águas. Suava frio, mas prolongava a tortura que produziam as picadas das pulgas e a imobilidade. Afinal as picadas das pulgas e a imobilidade me distrairiam daqueles beijos e daqueles uivos (RAMOS, 2003, p. 101).

Angústia é um livro que encena um drama que se poderia dizer da imobilidade. Encenação de "ideias", figuras, sombras que se movimentam no discurso da narrativa, porém imóveis em relação a uma história na qual elas desempenham papel coadjuvante.

O jogo de idas e vindas de ideias metaforiza o processo de escrita que tenta captar essa dialética de movimento e estagnação, botinas que tanto andaram e agora estão paradas num canto tortas; do "espírito de Deus" criador de todas as coisas que boia sobre as águas. Mesmo sendo rechaçadas, "algumas voltavam com insistência". Em suma, para evidenciar a imobilidade um movimento tem de ser representado, são as "picadas de pulgas" a ação da própria "imobilidade".

Pulgas, seres minúsculos, proliferam somente em ambientes favoráveis: úmidos e quentes, ou seja, em lugares com pouca higiene. Quente, úmido, estagnado, este é o palco em que a decadência representa o seu papel numa história inerte, desses personagens arruinados por uma outra história que se prefigura, se movimenta, porém, escapa-lhes e os põe à margem, boiando sobre as águas.

Apesar de tudo, "as picadas das pulgas e a imobilidade me distrairiam daqueles beijos e daqueles uivos" (RAMOS, 2003, p. 101). 


\section{Modernidade líquida}

Líquido se derramava: o homem triste enchia dornas (RAMOS, 2003, p. 54).

Diante dessa história que de um lado é imóvel, principalmente a dos personagens, do outro movimenta-se e escapa a quem tenta apreendê-la, seja para quem narra ou protagoniza os eventos. Nessas circunstâncias, as ações perdem significado: é uma criada Vitória que tenta educar um papagaio, acompanhar os movimentos dos navios no porto, enterrar dinheiro no quintal; homens e mulheres que enchem dornas; mulheres que mexem e remexem a terra como formigas; o narrador-protagonista reconstruindo os eventos.

Ações e histórias esvaziadas de significados conduzem a um emparedamento dos destinos. O salto para o determinismo está concretizado. Se os fatos já estão dados, o que resta fazer? A saída é a imobilidade, ficar parado observando o show da estagnação, as coisas serem carcomidas pela desagregação, pessoas reduzidas a objetos e a animais, descendo a uma condição inumana.

Da mesma forma que essa inércia parece estranha, ela é construção dos homens. E aqui reside a reificação em alto grau. Vê-se, pois, que a relações entre as pessoas são apagadas. Uma vez embaciadas, a história também o é. Portanto, fantasmagoricamente estas relações passam a ser entre coisas, não mais entre seres humanos. Daí a sensação de imobilismo, com atitudes e eventos sem significados. Não há o que se fazer. Talvez enxaguar as dornas do passado, remexer as terras do quintal das lembranças ou pegar um bonde cujo destino é a his tória, moderna e líquida.

\section{Considerações finais}

Já se escreveu muito sobre Angústia. Apesar de publicada há décadas, ainda causa fascínio e despertada curiosidades naqueles que mergulham em seu texto.

Talvez uma das razões mais evidentes desse interesse esteja na forma como o romance foi composto, em que as peculiaridades estilísticas são árdua $\mathrm{e}$ intencionalmente trabalhadas por Graciliano Ramos.

Fez-se, portanto, um processo de escrita em que a metáfora, metonímia e a comparação encenam todo um movimento numa história marcada pe la imobilidade.

Além desses recursos estilísticos, igualmente importantes foram mostrados o 
papel da descrição e a representação do outro, pois eles constituem também tanto o processo de escrita como a tentativa de apreensão dessa realidade que teima em e scapar e fugir das mãos.

Nesse sentido, ao resgatar Angústia em meio à produção do Graciliano Ramos, proponho atualizar a leitura da obra, pois esse é o papel que presumo ser o da crítica literária que se pretende dialética, e que de igual forma tenta captar as contradições da história em movimento em um país marcado pela imobilidade histórica.

\section{Referências}

CANDIDO, A. Ficção e confissão. Rio de Janeiro, José Olympio, 1956

CRISTÓVÃO, F. Graciliano Ramos: Estrutura e Valores de um Modo de Narrar. 3. ed. São Paulo: J. Olympio, 1986.

DACANAL, J. H. O romance de 30. 7. ed. rev. Porto Alegre: Mercado Aberto, 1982.

LODGE, David. A arte da ficção. Tradução de Guilherme da Silva Braga. Porto Alegre, RS: L\&PM, 2010.

MALARD, L. Ensaio de literatura brasileira: Ideologia e realidade em Graciliano Ramos. Belo Horizonte: Itatiaia, 1976.

PUCCINELLI, L. Graciliano Ramos: relações entre ficção e realidade. São Paulo, Quíron; Brasília: INL, 1975.

RAMOS, Graciliano. Angústia. Rio de Janeiro: O Globo; São Paulo: Folha de S. Paulo, 2003. 